\title{
EVALUASI FISIK SEDIAAN SUSPENSI DENGAN KOMBINASI SUSPENDING AGENT PGA (Pulvis Gummi Arabici) DAN CMC-Na (Carboxymethylcellulosum Natrium)
}

\section{(PHYSIC EVALUATION OF SUSPENSION WITH SUSPENDING AGENT COMBINATION OF PGA (pulvis gummi arabici) AND CMC-Na (Carboxymethylcellulosum Natrium))}

\author{
NI MADE DHARMA SHANTINI SUENA ${ }^{1 *}$ \\ ${ }^{1}$ Akademi Farmasi Saraswati Denpasar, Jalan Kamboja no. 11A, Denpasar, Bali
}

\begin{abstract}
Abstrak: Suspensi dibuat karena beberapa zat aktif obat mempunyai kelarutan yang praktis tidak larut dalam air, tetapi diperlukan dalam bentuk cair. Konsentrasi PGA sebagai suspending agent adalah 5-10\%, namun PGA pada konsentrasi kurang dari $10 \%$ memiliki viskositas yang rendah sehingga dapat mempercepat terjadinya sedimentasi. Oleh karena itu PGA dikombinasikan dengan CMC-Na yang merupakan suspending agent yang dapat meningkatkan viskositas serta dapat meningkatkan kestabilan suspensi. Sifat fisik yang diinginkan adalah suspensi memiliki partikel yang tidak cepat mengendap dan mudah diredispersi. Tujuan penelitian adalah untuk mengetahui karakteristik suspensi dengan kombinasi suspending agent PGA dan CMC-Na. Penelitian ini menggunakan metode eksperimental dengan pengolahan data secara deskriptif. Pada penelitian dibuat empat formula yaitu formula I, II, III, dan IV untuk diamati tampilan, warna, bau dan rasa, dihitung kecepatan dan volume sedimentasi yang terbentuk, serta diuji redispersibilitas dari masing-masing formula. Kombinasi PGA dan CMC-Na berturut-turut dari formula I, II, III, dan IV adalah 5\% dan 0,25\%; $3,75 \%$ dan $0,5 \% ; 2,5 \%$ dan $0,75 \% ; 1,25 \%$ dan $1 \%$. Hasil pengujian kecepatan sedimentasi formula I, II, III, dan IV berturut-turut adalah 0,$2318 ; 0,233 ; 0,124 ;$ dan $0,0021(\mathrm{~cm} / \mathrm{menit})$. Sedangkan hasil pengujian volume sedimentasi adalah 0,$031 ; 0,046 ; 0,152$; dan 0,554 . Hasil pengujian redispersibilitas yaitu $0 \% ; 0 \%$; $15 \%$; dan $50 \%$. Formula I dan II merupakan formula dengan sistem kombinasi dimana sistem deflokulasi lebih dominan sedangkan formula III dan IV juga merupakan formula dengan sistem kombinasi tetapi sistem flokulasi lebih dominan. Di akhir pengamatan, pada formula I dan IV tidak ada perubahan bau dan rasa sedangkan pada formula II dan III ada perubahan bau dan rasa.
\end{abstract}

Kata Kunci: suspensi, suspending agent, PGA, CMC-Na

\begin{abstract}
The suspension was made because of several active substances of drug are practically insoluble in water, but it is required in liquid drug form. Common concentration of PGA as a suspending agent is 5-10\%, but the PGA at a concentration of less than $10 \%$ has a low viscosity so that it can accelerate the sedimentation. Therefore PGA has to be combined with CMC-Na which can increase the viscosity and increase the stability of the suspension. The desired physical properties of suspension are that suspension has no particles that will sediment quickly and easily dispersed. The purpose of research is to determine the characteristics of the suspension with the suspending agent combination of PGA and CMC-Na. This study uses an experimental method with descriptive data processing. In the study were made four formulas which are formula I, II, III, and IV to be observed its appearance, color, smell and taste, calculated its speed and volume of the sediment formed, and tested the disperse ability of each formula. The combination of PGA and CMC-Na of formula I, II, III, and IV in a row is $5 \%$ and $0.25 \% ; 3.75 \%$ and $0.5 \% ; 2.5 \%$ and $0.75 \% ; 1.25 \%$ and $1 \%$. Test results sedimentation velocity of formula I, II, III, and IV respectively is $0.2318 ; 0.233 ; 0.124$; and $0.0021(\mathrm{~cm} / \mathrm{min})$. While the test results sedimentation volume were 0,$031 ; 0,046 ; 0.152$; and 0.554 . Test results of disperse ability were $0 \% ; 0 \% ; 15 \%$; and $50 \%$. Formula I and II is a formula with a combination system where the deflocculated system is more dominant, while formulas III and IV is also a formula with a combination system but the system is more dominant to flocculation. At the end of the observation, the formula I and IV had no change in odor and taste, while the formula II and III had a change in odor and taste.
\end{abstract}

Keywords: suspension, suspending agent, PGA, CMC-Na

\footnotetext{
* Penulis Korespondensi, Hp. 08563740032

e-mail: vrndaranyadasi@gmail.com
} 


\section{PENDAHULUAN}

Dalam bidang industri farmasi, perkembangan teknologi sangat berperan aktif dalam peningkatan kualitas produksi obat-obatan. Hal ini banyak ditunjukkan dengan banyaknya sediaan obat-obatan yang disesuaikan dengan karakteristik dari zat aktif obat, kondisi pasien, dan peningkatan kualitas obat. Menurut Priyambodo (2007), berdasarkan bentuk sediaannya, obat dapat digolongkan menjadi tiga macam, yaitu bentuk sediaan padat/solida, bentuk sediaan semipadat/semisolida, dan bentuk sediaan cair/liquida. Contoh dari bentuk sediaan padat/solida adalah tablet dan kapsul, sedangkan contoh dari bentuk sediaan semipadat/semisolida adalah salep, krim, jel, dan pasta. Contoh dari bentuk sediaan cair/liquida adalah larutan, suspensi, dan emulsi.

Suspensi merupakan salah satu contoh sediaan obat yang berbentuk cair terdiri atas bahan padat tidak larut namun dapat tersebar merata ke dalam pembawanya. Menurut Anonim (1979), suspensi adalah sediaan yang mengandung bahan obat padat dalam bentuk halus dan tidak larut, terdispersi dalam cairan pembawa. Zat yang terdispersi harus halus, tidak boleh cepat mengendap, dan bila dikocok perlahan-lahan, endapan harus terdispersi kembali. Beberapa ditambahkan zat tambahan untuk menjamin stabilitas suspensi tetapi kekentalan suspensi harus menjamin sediaan mudah dikocok dan dituang.

Bentuk sediaan suspensi diformulasikan karena beberapa zat aktif obat mempunyai kelarutan yang praktis tidak larut dalam air, tetapi diperlukan dalam bentuk cair agar mudah diberikan kepada pasien yang mengalami kesulitan untuk menelan, mudah diberikan pada anak-anak, serta untuk menutupi rasa pahit atau aroma yang tidak enak dari zat aktif obat. Alasan lain adalah karena air merupakan pelarut yang paling aman bagi manusia. Untuk itu air digunakan sebagai medium pembawa pada sebagian besar sediaan suspensi. Walaupun zat aktif obat memiliki kelarutan buruk dalam air, zat aktif obat tetap dapat dibuat ke dalam bentuk sediaan cair/liquida dengan adanya bantuan suspending agent.

Banyak hal yang perlu diperhatikan dalam mengembangkan suatu bentuk sediaan suspensi. Salah satunya adalah pemilihan suspending agent. Menurut Chaerunisaa dkk (2009), suspending agent dibagi menjadi beberapa golongan.
Golongan pertama adalah polisakarida yang terdiri dari gom akasia (gom arab)/PGA, tragakan, naalginat (sodium alginat), starch (amilum), karagen (chondrus extract), xanthan gum (polysaccharide b-1449/ corn sugar gum), serta guar gum (guar flour). Golongan kedua adalah turunan selulosa, contohnya metilselulosa, CMC-Na (karboksimetil selulosa), avicel, dan hidroksi etil selulosa. Golongan ketiga adalah clay misalnya bentonit, aluminium-magnesium silikat (veegum), dan hectocrite (salah satu senyawa mineral berbentuk tanah liat). Golongan keempat adalah polimer sintetik contohnya golongan carbomer.

Dalam penelitian ini, akan dilakukan formulasi suspensi menggunakan kombinasi suspending agent yaitu Pulvis Gummi Arabici (PGA) dan Carboxymethylcellulosum Natrium (CMC-Na). Menurut Rowe dkk (2009), konsentrasi PGA sebagai suspending agent adalah 5-10\%. Menurut Nussinovitch (1997) dalam Anggreini DB (2013), PGA pada konsentrasi kurang dari $10 \%$ memiliki viskositas yang rendah dapat mempercepat terjadinya sedimentasi yang menyebabkan sediaan menjadi tidak stabil. Oleh karena itu PGA dikombinasikan dengan CMC-Na yang merupakan suspending agent yang dapat meningkatkan viskositas serta dapat meningkatkan kestabilan dari suspensi yang dihasilkan.

\section{BAHAN DAN METODE}

Rancangan Penelitian. Penelitian ini adalah penelitian eksperimental dengan metode pengolahan data secara deskriptif. Perlakuan yang diberikan pada unit eksperimen yaitu mengombinasikan PGA dan CMC-Na dengan konsentrasi berbeda. Perlakuan ini dilakukan untuk mengetahui karakteristik suspensi dengan kombinasi suspending agent PGA dan CMC-Na terhadap tampilan, warna, bau, rasa, kecepatan sedimentasi, volume sedimentasi dan kemampuan redispersi.

Bahan. Bahan-bahan yang digunakan dalam penelitian ini antara lain:
1. Talk
2. PGA
$10 \mathrm{~g}$
3. $\mathrm{CMC}-\mathrm{Na}$
$12,5 \mathrm{~g}$
4. Gliserin
$2,5 \mathrm{~g}$
5. Sirop Gula
$40 \mathrm{ml}$
6. Aqua Destillata
$80 \mathrm{ml}$
$258 \mathrm{ml}$ 
Formulasi suspensi.

Tabel 1. Formulasi suspensi dengan Kombinasi Suspending Agent PGA dan CMC-Na

\begin{tabular}{|c|c|c|c|c|c|}
\hline \multirow[t]{2}{*}{ Bahan } & \multicolumn{4}{|c|}{ Konsentrasi (\%) } & \multirow[t]{2}{*}{ Fungsi } \\
\hline & F I & F II & F III & F IV & \\
\hline Talk & 2,5 & 2,5 & 2,5 & 2,5 & Bahan aktif \\
\hline PGA & 5 & 3,75 & 2,5 & 1,25 & $\begin{array}{l}\text { Suspending } \\
\text { agent }\end{array}$ \\
\hline $\mathrm{CMC}-\mathrm{Na}$ & 0,25 & 0,5 & 0,75 & 1 & $\begin{array}{l}\text { Suspending } \\
\text { agent }\end{array}$ \\
\hline Gliserin & 10 & 10 & 10 & 10 & $\begin{array}{l}\text { Wetting } \\
\text { agent }\end{array}$ \\
\hline $\begin{array}{l}\text { Sirop } \\
\text { Gula }\end{array}$ & 20 & 20 & 20 & 20 & Pemanis \\
\hline $\begin{array}{l}\text { Aqua } \\
\text { Destillata }\end{array}$ & 63 & 64 & 65 & 66 & $\begin{array}{l}\text { Cairan } \\
\text { pembawa }\end{array}$ \\
\hline
\end{tabular}

Pembuatan suspensi. Sediaan suspensi terdiri dari empat formula (Tabel 1). PGA dan CMC-Na digerus sampai homogen kemudian dilarutkan dengan air sampai terbentuknya mucilago, kemudian bahan yang akan dibuat suspensi ditambahkan gliserin dan digerus sampai homogen pada mortir dan stamper lain. Campuran bahan yang akan dibuat suspensi dan gliserin dituang sedikit demi sedikit ke dalam larutan PGA dan CMC-Na sambil diaduk sampai homogen. Setelah itu, dimasukkan ke dalam gelas ukur beserta dengan air bilasan dari mortir dan ditambahkan sirop gula. Terakhir ditambahkan Aqua destillata hingga $100 \mathrm{ml}$.

Pengamatan tampilan. Pengamatan tampilan dilakukan secara manual dengan pencahayaan masing-masing formula dalam gelas ukur dengan senter dari hari pertama sampai hari ke tujuh. Pokok pengamatannya adalah warna dan tampilan sedimen, tingkat kekeruhan, serta terbentuknya cake/endapan.

Pengamatan warna, bau, dan rasa. Pengamatan warna dilakukan secara manual dengan pencahayaan masing-masing formula dalam gelas ukur dengan senter dari hari pertama sampai hari ke tujuh, sedangkan pengamatan bau dan rasa dilakukan di awal dan di akhir pengujian.

Perhitungan kecepatan sedimentasi dan volume sedimentasi, serta pengujian redispersibilitas. Suspensi disimpan dalam gelas ukur dengan keadaan tidak terganggu. Suspensi tersebut diukur meliputi tinggi suspensi, tinggi sedimentasi, volume suspensi, serta volume akhir sedimentasi dari hari pertama sampai hari ke tujuh. Data yang didapat, digunakan untuk menghitung kecepatan dan volume sedimentasi.

Kecepatan sedimentasi dihitung menggunakan rumus umum kecepatan yaitu persamaan satu (1) sedangkan untuk mengukur rasio volume akhir endapan terhadap volume awal dari suspensi (volume sedimentasi) digunakan persamaan dua (2).

$\mathrm{V}=\Delta \mathrm{s} / \Delta \mathrm{t}$................Persamaan 1 (Hartanto, 2010) $\mathrm{F}=\mathrm{Vu} / \mathrm{Vo}$...........Persamaan 2 (Martin dkk, 2008) Pengujian redispersibilitas dilakukan secara manual dengan menggojok silinder setelah terjadi sedimentasi. Satu kali inversi menyatakan bahwa suspensi $100 \%$ mudah teredisperi. Setiap penambahan inversi mengurangi persen kemudahan redispersi sebanyak 5\% seluruh sediaan (Anggreini, 2013).

\section{HASIL DAN PEMBAHASAN}

Pengamatan Tampilan.

Tabel 2. Tampilan Suspensi dengan Kombinasi Suspending agent PGA dan CMC-Na

\begin{tabular}{|c|c|c|c|c|}
\hline Hari & FI & FII & FIII & FIV \\
\hline $15^{\prime}$ & $+\sqrt{ } \sqrt{ } \sqrt{ } \sqrt{ }$ & $+\sqrt{\sqrt{ } \sqrt{ } \sqrt{ }}$ & $-\sqrt{\sqrt{ } \sqrt{ } \sqrt{ }}$ & $-\sqrt{\sqrt{ } \sqrt{ } \sqrt{ }}$ \\
\hline $30^{\prime}$ & $+\sqrt{ } \sqrt{ } \sqrt{ } \sqrt{ }$ & $+\sqrt{ } \sqrt{ } \sqrt{ } \sqrt{ }$ & $+\sqrt{ } \sqrt{ } \sqrt{ } \sqrt{ }$ & $-\sqrt{ } \sqrt{ } \sqrt{ } \sqrt{ }$ \\
\hline $45^{\prime}$ & $+\sqrt{ } \sqrt{ } \sqrt{ } \sqrt{ }$ & $+\sqrt{ } \sqrt{ } \sqrt{ } \sqrt{ }$ & $+\sqrt{ } \sqrt{ } \sqrt{ } \sqrt{ }$ & $-\sqrt{ } \sqrt{ } \sqrt{ } \sqrt{ }$ \\
\hline $60^{\prime}$ & $+\sqrt{ } \sqrt{ } \sqrt{ } \sqrt{ }$ & $+\sqrt{ } \sqrt{ } \sqrt{ } \sqrt{ }$ & $+\sqrt{ } \sqrt{ } \sqrt{ } \sqrt{ }$ & $-\sqrt{ } \sqrt{ } \sqrt{ } \sqrt{ }$ \\
\hline II & $+\sqrt{ } \sqrt{ } \sqrt{ }$ & $+\sqrt{ } \sqrt{ } \sqrt{ } \sqrt{ }$ & $+\sqrt{ }$ & $+\sqrt{ } \sqrt{ }$ \\
\hline III & $+\sqrt{ } \sqrt{ } \sqrt{ }$ & $+\sqrt{ } \sqrt{ } \sqrt{ } \sqrt{ }$ & $+\sqrt{ }$ & $+\sqrt{ } \sqrt{ }$ \\
\hline IV & $+\sqrt{ } \sqrt{ } \sqrt{ }$ & $+\sqrt{ } \sqrt{ } \sqrt{ } \sqrt{ }$ & $+\sqrt{ }$ & $+\sqrt{ } \sqrt{ }$ \\
\hline V & $+\sqrt{ } \sqrt{ } \sqrt{ }$ & $+\sqrt{ } \sqrt{ } \sqrt{ } \sqrt{ }$ & $+\sqrt{ }$ & $+\sqrt{ } \sqrt{ }$ \\
\hline VI & $+\sqrt{ } \sqrt{ } \sqrt{ }$ & $+\sqrt{ } \sqrt{ } \sqrt{ }$ & $+\sqrt{ }$ & $+\sqrt{ } \sqrt{ }$ \\
\hline VII & $+\sqrt{ } \sqrt{ } \sqrt{o}_{0}$ & $+\sqrt{ } \sqrt{ } \sqrt{ }{ }_{0}$ & $+\sqrt{ }$ & $+\sqrt{ } \sqrt{ }$ \\
\hline
\end{tabular}

Keterangan: $+=$ sedimen terlihat sama, $-=$ belum terbentuk sedimen, $\mathrm{o}=$ cake,

$\sqrt{ }=$ tingkat kekeruhan

Pengamatan Warna, Bau, dan Rasa.

Tabel 3. Warna Suspensi dengan Kombinasi Suspending agent PGA dan CMC-Na

\begin{tabular}{|c|c|c|c|c|c|}
\hline \multicolumn{2}{|c|}{ Hari } & FI & FII & FIII & FIV \\
\hline $\mathbf{I}$ & $15^{\prime}$ & - & - & - & - \\
\hline & $30^{\prime}$ & - & - & - & - \\
\hline & $45^{\prime}$ & - & - & - & - \\
\hline & $60^{\prime}$ & - & - & - & - \\
\hline & & - & - & - & - \\
\hline & & - & - & - & - \\
\hline & & - & - & - & - \\
\hline & & - & - & - & - \\
\hline & & - & - & - & - \\
\hline & & - & - & - & - \\
\hline
\end{tabular}

Keterangan: - = warna tidak berubah

Tabel 4. Bau dan Rasa Suspensi dengan Kombinasi Suspending agent PGA dan CMC-Na

\begin{tabular}{lllll}
\hline Hari & FI & FII & FIII & FIV \\
\hline I & Bau khas & Bau khas & Bau khas & Bau \\
& dan rasa & dan rasa & dan rasa & khas \\
& manis & manis & manis & $\begin{array}{l}\text { dan } \\
\text { rasa } \\
\end{array}$ \\
& & & manis \\
\hline
\end{tabular}




\begin{tabular}{lllll}
\hline Hari & FI & FII & FIII & FIV \\
\hline VII & Bau khas & Bau dan & Bau dan & Bau \\
& dan rasa & rasa & rasa & khas \\
& manis & kurang & tidak & dan \\
& & sedap & sedap & rasa \\
& & & & manis \\
\hline
\end{tabular}

Keterangan: bau dan rasa diamati di awal dan di akhir

Perhitungan Kecepatan Sedimentasi dan Volume Sedimentasi, serta Pengujian Redispersibilitas.

Tabel 5. Tinggi Sedimentasi Suspensi dengan Kombinasi Suspending agent PGA dan CMC-Na

\begin{tabular}{ccclll}
\hline \multicolumn{2}{c}{ Hari } & \multicolumn{1}{c}{ FI } & \multicolumn{1}{c}{ FII } & FIII & \multicolumn{1}{c}{ FIV } \\
\hline I & $15^{\prime}$ & $0,4 \mathrm{~cm}$ & $0,1 \mathrm{~cm}$ & - & - \\
& 30, & $0,6 \mathrm{~cm}$ & $0,6 \mathrm{~cm}$ & $0,1 \mathrm{~cm}$ & - \\
$45^{\prime}$ & $0,6 \mathrm{~cm}$ & $0,7 \mathrm{~cm}$ & $0,1 \mathrm{~cm}$ & - \\
60 & $0,7 \mathrm{~cm}$ & $1 \mathrm{~cm}$ & $0,3 \mathrm{~cm}$ & - \\
II & $0,7 \mathrm{~cm}$ & $1,4 \mathrm{~cm}$ & $1,7 \mathrm{~cm}$ & $5,5 \mathrm{~cm}$ \\
III & $0,7 \mathrm{~cm}$ & $1,4 \mathrm{~cm}$ & $1,7 \mathrm{~cm}$ & $4,5 \mathrm{~cm}$ \\
IV & $0,6 \mathrm{~cm}$ & $0,8 \mathrm{~cm}$ & $1,4 \mathrm{~cm}$ & $4 \mathrm{~cm}$ \\
V & $0,6 \mathrm{~cm}$ & $0,8 \mathrm{~cm}$ & $1,2 \mathrm{~cm}$ & $4 \mathrm{~cm}$ \\
VI & $0,6 \mathrm{~cm}$ & $0,8 \mathrm{~cm}$ & $1,2 \mathrm{~cm}$ & $3,5 \mathrm{~cm}$ \\
VII & $0,6 \mathrm{~cm}$ & $0,6 \mathrm{~cm}$ & $1,2 \mathrm{~cm}$ & $3,4 \mathrm{~cm}$ \\
\hline
\end{tabular}

Rumus: $V=\frac{\Delta s}{\Delta t}$

Keterangan:

$\mathrm{V}=\operatorname{kecepatan}(\mathrm{cm} / \mathrm{menit})$

$\Delta \mathrm{s}=$ perpindahan $(\mathrm{cm})$

$\Delta \mathrm{t}=$ selang waktu (menit)

Diketahui: $\mathrm{s}_{1}=17 \mathrm{~cm}$

Tabel 6. Kecepatan Sedimentasi Suspensi dengan Kombinasi Suspending agent PGA dan CMC-Na

\begin{tabular}{crrrll}
\hline \multicolumn{2}{c}{ Hari } & FI & FII & FIII & FIV \\
\hline I & $15^{\prime}$ & 1,107 & 1,127 & 0 & 0 \\
& 30 & 0,547 & 0,547 & 0,563 & 0 \\
& $45^{\prime}$ & 0,364 & 0,362 & 0,376 & 0 \\
& 60 & 0,272 & 0,267 & 0,278 & 0 \\
& II & 0,011 & 0,011 & 0,011 & 0,008 \\
& III & 0,006 & 0,005 & 0,005 & 0,004 \\
IV & 0,004 & 0,004 & 0,004 & 0,003 \\
& V & 0,003 & 0,003 & 0,003 & 0,002 \\
& VI & 0,002 & 0,002 & 0,002 & 0,002 \\
\multicolumn{2}{c}{ VII } & 0,002 & 0,002 & 0,002 & 0,002 \\
\multicolumn{2}{l}{ Rata-rata } & 0,2318 & 0,233 & 0,124 & 0,0021 \\
\hline
\end{tabular}

Tabel 7. Volume Akhir Sedimentasi Suspensi dengan Kombinasi Suspending agent PGA dan CMC-Na

\begin{tabular}{llrrrr}
\hline \multicolumn{2}{c}{ Hari } & FI & \multicolumn{1}{c}{ FII } & \multicolumn{1}{c}{ FIII } & \multicolumn{1}{c}{ FIV } \\
\hline I & $15^{\prime}$ & $1 \mathrm{ml}$ & $0,3 \mathrm{ml}$ & $100 \mathrm{ml}$ & $100 \mathrm{ml}$ \\
& 30, & $3 \mathrm{ml}$ & $3 \mathrm{ml}$ & $0,3 \mathrm{ml}$ & $100 \mathrm{ml}$ \\
& $45^{\prime}$ & $3 \mathrm{ml}$ & $4 \mathrm{ml}$ & $0,3 \mathrm{ml}$ & $100 \mathrm{ml}$ \\
& $60^{\prime}$ & $4 \mathrm{ml}$ & $7 \mathrm{ml}$ & $1 \mathrm{ml}$ & $100 \mathrm{ml}$ \\
II & & $4 \mathrm{ml}$ & $8 \mathrm{ml}$ & $10 \mathrm{ml}$ & $34 \mathrm{ml}$ \\
III & & $4 \mathrm{ml}$ & $8 \mathrm{ml}$ & $10 \mathrm{ml}$ & $28 \mathrm{ml}$ \\
IV & & $3 \mathrm{ml}$ & $5 \mathrm{ml}$ & $9 \mathrm{ml}$ & $25 \mathrm{ml}$ \\
V & $3 \mathrm{ml}$ & $4 \mathrm{ml}$ & $7 \mathrm{ml}$ & $24 \mathrm{ml}$ \\
VI & $3 \mathrm{ml}$ & $4 \mathrm{ml}$ & $7 \mathrm{ml}$ & $22 \mathrm{ml}$ \\
VII & $3 \mathrm{ml}$ & $3 \mathrm{ml}$ & $7 \mathrm{ml}$ & $21 \mathrm{ml}$ \\
\hline
\end{tabular}

Rumus: $\mathrm{F}=\mathrm{Vu} / \mathrm{Vo}$

Keterangan:

F : volume sedimentasi

$\mathrm{Vu} \quad$ : volume akhir endapan/sedimentasi (ml)

Vo : volume awal suspensi $(\mathrm{ml})$

Jadi diperoleh hasil:

Tabel 8. Volume Sedimentasi Suspensi dengan Kombinasi Suspending agent PGA dan CMC-Na

\begin{tabular}{ccclll}
\hline \multicolumn{2}{c}{ Hari } & FI & \multicolumn{1}{c}{ FII } & FIII & FIV \\
\hline I & $15^{\prime}$ & 0,01 & 0,003 & 1 & 1 \\
& 30 & 0,03 & 0,03 & 0,003 & 1 \\
& $45^{\prime}$ & 0,03 & 0,04 & 0,003 & 1 \\
& 60 & 0,04 & 0,07 & 0,01 & 1 \\
& II & 0,04 & 0,08 & 0,1 & 0,34 \\
& III & 0,04 & 0,08 & 0,1 & 0,28 \\
& IV & 0,03 & 0,05 & 0,09 & 0,25 \\
& V & 0,03 & 0,04 & 0,07 & 0,24 \\
& VI & 0,03 & 0,04 & 0,07 & 0,22 \\
& VII & 0,03 & 0,03 & 0,07 & 0,21 \\
\multicolumn{2}{l}{ Rata-rata } & 0,031 & 0,046 & 0,152 & 0,554 \\
\hline
\end{tabular}

Tabel 9. Pengujian Redispersibilitas Suspensi dengan Kombinasi Suspending agent PGA dan CMC-Na

\begin{tabular}{cc}
\hline Formula suspensi & Pengojokan \\
\hline FI & Caking $/ 0 \%$ \\
FII & Caking $/ 0 \%$ \\
FIII & $17 \mathrm{kali} / 15 \%$ \\
FIV & $10 \mathrm{kali} / 50 \%$ \\
\hline
\end{tabular}

Kestabilan fisik suspensi adalah hambatan utama dalam memformulasikan suspensi karena masalah yang sering terjadi meliputi kecepatan sedimentasi yang tinggi maupun kemampuan redispersi yang buruk. Oleh karena itu diperlukan penggunaan suspending agent untuk meningkatkan kestabilan fisik suspensi. Dalam penelitian ini, setiap formula suspensi menggunakan kombinasi suspending agent yaitu Pulvis Gummi Arabici (PGA) dan Carboxymethylcellulosum Natrium (CMC-Na). Menurut Anggreini (2013), pemilihan suspending agent didasarkan pada karakteristik suspending agent yaitu dapat meningkatkan kekentalan untuk membentuk suspensi yang ideal, bersifat kompatibel dengan eksipien lain, dan tidak toksik.

Penelitian yang dilakukan meliputi pengamatan tampilan, warna, bau, dan rasa, perhitungan volume sedimentasi, kecepatan sedimentasi, dan pengujian redispersibilitas. Pengamatan tampilan, warna, bau, dan rasa dilakukan untuk mengetahui perbedaan tampilan, warna, bau, dan rasa dari masing-masing formula. Perhitungan volume sedimentasi dilakukan untuk mengetahui rasio pengendapan yang terjadi selama penyimpanan pada waktu tertentu, sedangkan perhitungan kecepatan sedimentasi dilakukan untuk 
mengetahui hasil bagi antara perpindahan zat yang terdispersi dalam selang waktu tertentu. Pengujian redispersibilitas dilakukan untuk mengetahui kemampuan suspensi untuk teredispersi dengan pengojokan.

Percobaan ini dilakukan dengan membuat suspensi dengan formulasi PGA dan CMC-Na, gliserin, sirop gula, serta air sebagai pembawa. PGA dan CMC-Na berfungsi sebagai suspending agent, gliserin berfungsi sebagai wetting agent/agen pembasah, dan sirop gula berfungsi sebagai pemanis. Suspensi ini dibuat dengan metode dispersi karena talk merupakan senyawa yang tidak larut dalam hampir semua pelarut sehingga ditambahkan gliserin agar mudah dibasahi. Menurut Priyambodo (2007), zat-zat hidrofobik sangat sukar untuk terdispersi dan seringkali mengambang pada permukaan cairan karena pembasahan cairan yang jelek. Menurut Lachman dkk (2012), prinsip metode dispersi adalah pembawa harus diformulasikan agar fase padat dengan mudah dibasahi dan didispersikan. Dalam hal ini surfaktan dapat digunakan untuk menjamin pembasahan zat padat hidrofobik dengan seragam.

Hasil pengujian dan pengamatan menunjukkan bahwa formula I dan II merupakan formula dengan kombinasi sistem flokulasi dan deflokulasi dimana sistem deflokulasi lebih dominan. Di akhir pengamatan sedimen menjadi sangat kompak (cake) sehingga tidak dapat didispersikan kembali. Suspensi menunjukkan tampilan yang menyenangkan (bagus) dengan cairan yang masih keruh walaupun sedimentasi terjadi secara tampak. Sifat tersebut merupakan sifat dari sistem deflokulasi, sedangkan sifat dari sistem flokulasi yang muncul adalah sedimen terbentuk secara cepat. Hasil pengujian kecepatan sedimentasi formula I adalah sebesar 0,2318 $\mathrm{cm} /$ menit dan formula II sebesar $0,233 \mathrm{~cm} /$ menit. Tidak ada perubahan bau dan rasa pada formula I, sedangkan timbul bau dan rasa kurang sedap pada formula II.

Formula III dan IV juga merupakan formula dengan kombinasi sistem flokulasi dan deflokulasi dimana sistem flokulasi lebih dominan. Sifat dari sistem deflokulasi yang muncul pada kedua formula tersebut adalah sedimen terbentuk lambat, sedangkan sifat dari sistem flokulasi yang muncul yaitu suspensi tidak terlihat karena cairan berwarna jernih, partikel membentuk agregat longgar sehingga sedimen dapat diredispersi. Hasil pengujian redispersibilitas yaitu $15 \%$ untuk formula III dan 50\% untuk formula IV. Di akhir pengamatan timbul bau dan rasa tidak sedap pada formula III sedangkan pada formula IV tidak timbul bau dan rasa tidak sedap. Hasil pengujian kecepatan sedimentasi formula III adalah sebesar $0,124 \mathrm{~cm} /$ menit dan formula IV sebesar 0,0021 $\mathrm{cm} /$ menit.

F merupakan volume sedimentasi dengan nilai $\mathrm{F}$ adalah 1 menunjukkan bahwa partikel suspensi yang dihasilkan terdispersi merata dalam cairan pembawanya. Menurut Hui (1992) dalam Meliala dkk (2014), gum arab/PGA memiliki keunikan karena kelarutannya yang tinggi dan viskositasnya rendah. Menurut Adinugraha dkk (2005) dalam Nisa dan Putri (2014), CMC-Na bersifat hidrofilik dimana partikel akan menyerap air dan terjadi pembengkakan. Air yang sebelumnya ada di luar granula dan bebas bergerak, tidak dapat bergerak lagi dengan bebas sehingga keadaan larutan lebih mantap dan terjadi peningkatan viskositas. Menurut Agoes (2012), viskositas yang lebih besar dari medium dispersi akan memberikan keuntungan sedimentasi yang lebih lambat.

Pengujian redispersibilitas dipengaruhi oleh partikel yang terbentuk dalam suatu sistem suspensi. Apabila partikel berada sebagai satuan terpisah maka partikel akan membentuk sedimen yang sangat kompak (cake) sehingga sediaan akan sulit diredispersi, sedangkan partikel dengan agregat longgar menyebabkan partikel tidak terikat secara ketat antara satu dengan yang lainnya maka suspensi tidak membentuk massa yang keras dan rapat sehingga sediaan masih dapat teredispersi secara homogen dan membentuk suspensi aslinya.

Suspensi yang ideal adalah suspensi yang memenuhi persyaratan. Menurut Farmakope Indonesia Edisi III (1979), persyaratan suspensi adalah:

1. Zat yang terdispersi harus halus dan tidak boleh mengendap

2. Jika dikocok perlahan-lahan, endapan harus segera terdispersi kembali

3. Dapat mengandung zat tambahan untuk menjamin stabilitas suspensi

4. Kekentalan suspensi tidak boleh terlalu tinggi agar sedimen mudak dikocok dan dituang.

Pada penelitian ini volume sedimentasi (F) dicari nilai paling besar karena suspensi yang ideal memiliki nilai volume sedimentasi mendekati 1 , sedangkan redispersibilitas juga dicari nilai paling besar dengan nilai mendekati $100 \%$ karena suspensi yang baik memiliki kemampuan untuk teredispersi dengan sedikit pengojokan. 


\section{SIMPULAN}

Berdasarkan penelitian yang telah dilakukan maka dapat disimpulkan bahwa:

1. Hasil pengujian kecepatan sedimentasi formula I adalah 0,2318 cm/menit. Sedangkan hasil pengujian volume sedimentasi adalah 0,031. Hasil pengujian redispersibilitas yaitu $0 \%$ (cake). Tidak ada perubahan bau dan rasa di akhir pengamatan.

2. Hasil pengujian kecepatan sedimentasi formula II adalah $0,233 \mathrm{~cm} /$ menit. Sedangkan hasil pengujian volume sedimentasi 0,046. Hasil pengujian redispersibilitas yaitu $0 \%$ (cake). Ada perubahan bau dan rasa di akhir pengamatan.

3. Hasil pengujian kecepatan sedimentasi formula III adalah $0,124 \mathrm{~cm} /$ menit. Sedangkan hasil pengujian volume sedimentasi adalah 0,152 . Hasil pengujian redispersibilitas yaitu $15 \%$. Ada perubahan bau dan rasa di akhir pengamatan.

4. Hasil pengujian kecepatan sedimentasi formula IV adalah $0,0021 \mathrm{~cm} /$ menit. Sedangkan hasil pengujian volume sedimentasi adalah 0,554. Hasil pengujian redispersibilitas yaitu $50 \%$. Tidak ada perubahan bau dan rasa di akhir pengamatan.

\section{DAFTAR PUSTAKA}

Adinugraha MP dkk, 2005, Synthesis and Characterization of Sodium Carboxymethyl Cellulose From Cavendish Banana Pseudo Stem (Musa Cavendishii LAMBERT), Carbohydrate Polymers, 62: 164-169.

Agoes G, 2012, Sediaan Farmasi LiquidaSemisolida (SFI-7), Penerbit ITB Bandung, 124, 142-143.
Anggreini DB, 2013, Optimasi Formula Suspensi Siprofloksasin Menggunakan Kombinasi Pulvis Gummi Arabici (Pga) Dan Hydroxypropyl Methylcellulose (Hpmc) Dengan Metode Desain Faktorial, Skripsi tidak dipublikasikan, Pontianak, Program Studi Farmasi Fakultas Kedokteran Universitas Tanjungpura Pontianak.

Anonim, 1979, Farmakope Indonesia Edisi III, Departemen Kesehatan RI, Jakarta, 32, 96, 271, 567, 591.

Chaerunisaa AY, 2009, Farmasetika Dasar, Widya Padjajaran, Bandung, 95-97.

Hui YH, 1992, Encyclopedia of Food Science and Technology, Volume II, John Willey and Sons Inc, Canada.

Lachman L, Lieberman AH, Kanig LJ, 2008, Teori Dan Praktek Fisika Farmasi Industri III, Terjemahan oleh Siti Suyatmi, 1994, Jakarta, UI-Press.

Nisa D, Putri RDW, 2014, Pemanfaatan Selulosa dari Kulit Buah Kakao sebagai Bahan Baku Pembuatan CMC, Jurnal Pangan dan Agroindustri, Vol. 2 No. 3 p. 34-42, (online)

Nussinovitch A, 1997, Hydrocolloid Applications Chapman \& Hall, UK, hal 128.

Priyambodo B, 2007, Manajemen Farmasi Industri, Global Pustaka Utama, Yogyakarta, 116, 190-191.

Rowe CR, Sheskey JP, Quinn EM, 2009, Handbook of Pharmaceutical Excipients $6^{\text {th }}$ $E d$, Washington, American Pharmacists Association. 